FAVRET-SAADA, Jeanne. Comment produire une crise mondiale avec douze petits dessins. Paris: Les Prairies ordinaires éditions, 2007, 169 pp.

\title{
O CASO Das Charges de MaOmé E O Debate público Europeu SOBRE AS RELAÇÕES ENTRE "ISLAMISMO" E "OCIDENTE"
}

\author{
Paola Lins de Oliveira
}

No dia 30 de setembro de 2005, o jornal dinamarquês Jyllands-Posten publicou doze desenhos tematizando a figura do profeta Maomé, entre eles, caricaturas. De imediato, os responsáveis pela publicação receberam ameaças anônimas, enquanto imãs dinamarqueses manifestaram sua indignação alegando ter havido ofensa contra o sentimento religioso dos muçulmanos. Em resposta, o jornal invocou o direito à liberdade de expressão, argumento que recebeu apoio do governo dinamarquês. Nos quatro meses seguintes, o "Caso das Charges de Maomé", como ficou internacionalmente conhecido o episódio, alastrou-se na Europa e nos países de maioria muçulmana: embaixadores muçulmanos sediados na Dinamarca são chamados de volta aos seus países de origem, produtos dinamarqueses são boicotados, embaixadas dinamarquesas e da União Européia, atacadas. As manifestações dos grupos religiosos ofendidos intensificaram-se quando, em fevereiro de 2006, a imprensa de diversos países da Europa continental republicou os desenhos, tomando para si a causa.

Em Comment produire une crise moundiale avec douze petits dessins, Jeanne Favret-Saada analisa o caso reconstruindo o espaço e os modos de atuação de agentes religiosos, políticos e midiáticos com ampla repercussão nos meios de comunicação internacionais. Neste empreendimento, a antropóloga renova seu interesse em torno de situações de conflito e acusações envolvendo uma temática religiosa, assunto que perpassa sua produção acadêmica. Entre seus trabalhos mais representativos, destacam-se Les Mots, la Mort, les Sorts ${ }^{1}$, fruto de uma pesquisa etnográfica de dez anos sobre a feitiçaria em uma região rural francesa, e também a proposta de elaboração de uma "antropologia da blasfêmia" apresentada em um artigo ${ }^{2}$ inspirado nas reações provocadas pelo "Caso Rushdie" e outros episódios envolvendo produções artísticas acusadas de blasfêmia. É neste último trabalho que Favret-Saada desenvolve seu "dispositivo judiciário", instrumento conceitual que permitiria deslocar o foco da análise do acusado e de seu ato blasfemo para o acusador e o modo como este organiza e condena a ação a partir de um conjunto de interpretações e sanções teológicas potenciais. 
Esse método de revelação de um processo jurídico-social de denúncia e condenação públicas aparece como fio condutor também da análise desenvolvida por Favret-Saada na obra aqui resenhada. Talvez por isso, o exame do "caso das charges" proposto em Comment produire une crise moundiale não esmiúça as doze imagens que tematizam o islã e o Profeta Maomé como suportes de um ato ofensivo, blasfemador em si mesmo. Interessa a Favret-Saada reconstruir, por um lado, as bases sócio-históricas de um contexto específico que teria levado à irrupção do episódio, e por outro, o desdobramento de ações e reações desencadeadas a partir da publicação das imagens tanto na Europa quanto em diversos países do mundo árabe.

Em um comentário de apresentação à sua obra ${ }^{3}$, Favret-Saada afirma que todo o engajamento dos líderes muçulmanos na Europa e fora dela, assim como as respostas dos governos europeus, incluindo-se ainda as rebeliões, passeatas, destruição de prédios públicos e outros atos violentos devem ser contextualizados em um panorama mais geral de crise de relações entre, de um lado, imigrantes muçulmanos na Europa e seus parceiros/correligionários no mundo muçulmano; e de outro, os Estados europeus instigados a lidar com as diferenças políticas e culturais características desses grupos.

Logo no começo do livro, a autora explicita sua posição no debate: não pretende tomar o partido do islamismo e defende a perspectiva de que todas as religiões devem aceitar as instituições seculares. Desse ponto de vista, seu ensaio postula a existência "de uma comunidade de cidadãos, de um 'nós' a-cultural e areligioso que reúne todos aqueles que, ao redor do mundo, aderem ao princípio de separação da sociedade civil e da sociedade religiosa" (:9). Tal princípio, que fundamenta a laicidade francesa, seria comum a todas as sociedades democráticas e sempre que a fronteira entre funções religiosas e funções políticas forem ultrapassadas, segundo a autora, caberia "velar pela defesa das liberdades, e se for o caso, de lembrar tal necessidade aos nossos governantes tanto quanto às instituições internacionais" (:10).

No primeiro capítulo da obra, a autora recupera as origens dos valores democráticos na Dinamarca para ressaltar a profunda transformação ideológica que tornou o país internacionalmente reconhecido por sua atuação em prol das grandes causas humanitárias. Uma "imagem idílica" (:19) passa a representar o país, sobretudo após a Segunda Guerra mundial, e internamente, predomina uma atmosfera de "milagre político e social" caracterizada sobretudo pela alta participação eleitoral, grande atuação da sociedade civil, imprensa forte, e um estado providência que assegura uma coesão social expressiva.

Por volta do final dos anos de 1960, a economia dinamarquesa em expansão contrata trabalhadores estrangeiros vindos sobretudo da Turquia, Paquistão e Marrocos. Mesmo com a crise do petróleo da década seguinte, o fluxo de imigração mantém um aumento, não muito significativo, até 1983, quando uma lei de imigração considerada flexível é aprovada e o contingente de imigrantes aumenta vinte e seis vezes em uma década. 
A flexibilização da legislação de imigração não foi acompanhada de uma política social de integração dos muçulmanos, o que resultou em um progressivo aumento da visibilidade das diferenças culturais. Ainda que a opinião pública em geral aprovasse a legislação e se orgulhasse de não ser racista, focos de xenofobia e nacionalismo começaram a surgir. Em 1995, é fundado o Partido do Povo Dinamarquês, com uma agenda que condensa pretensões neoliberais de enxugamento do Estado, fortalecimento do nacionalismo perante a União Européia e o "retorno a uma sociedade monocultural" (:29), incluindo aqui a criação de uma nova legislação que limitasse tanto o afluxo de imigrantes quanto os direitos civis daqueles que residiam na Dinamarca. A partir dos atentados de setembro de 2001 esta bandeira contrária ao multiculturalismo ganha representatividade expressiva: "em poucas semanas, a opinião pública dinamarquesa é tomada pelo medo do Islã" (:32).

O segundo capítulo apresenta dados referentes ao aumento do fluxo de imigração conseqüente da legislação de 1983, enfatizando a dinâmica de ocupação do país pelos muçulmanos. Favret-Saada ressalta que tal política migratória tornou o país refúgio de muçulmanos e jihadistas, líderes religiosos que defendem "métodos violentos para a propagação do islamismo" (:39). Para ela, os discursos separatistas de tais líderes, que preconizam a rejeição do "ocidente" e a união dos imigrantes em uma "comunidade islâmica" com valores morais e políticos irredutíveis contribui para a clivagem entre muçulmanos e dinamarqueses (:39).

Entretanto, mesmo com toda a mobilização política em torno da "questão muçulmana" na Dinamarca, Favret-Saada ressalta a fragilidade das bases do debate público em torno do tema. A proibição de perguntas sobre religião nos censos nacionais, por exemplo, faz com que estimativas sejam baseadas no critério de origem nacional, considerando como 'muçulmanos' todos os indivíduos originários de países islâmicos e seus descendentes. Dessa forma, a estimativa de que eles corresponderiam a $3 \%$ da população em 2002, número bastante tímido aliás, poderia ser ainda menor já que se estima que destes, somente 10 ou 20\% sejam praticantes da religião. Entretanto, ainda que o número de muçulmanos praticantes seja pequeno, isto não diminuiu o perigo de confronto conseqüente da posição antagônica dos líderes islâmicos e seus seguidores em relação à cultura política dinamarquesa. Alguns líderes islâmicos passam a ocupar cada vez mais espaço nos meios de comunicação e no campo político, com sua "agenda" anti-democrática e em defesa dos direitos religiosos muçulmanos (:51).

No terceiro capítulo, Favret-Saada remonta o campo político dinamarquês no período imediatamente anterior à publicação dos desenhos, enfatizando o aumento da participação dos líderes muçulmanos a partir do incentivo do próprio governo dinamarquês e do Primeiro Ministro Fogh Rasmussen. Porém, mais uma vez a condução da política pública direcionada aos muçulmanos é abalada, quando um ano após os atentados de Madrid em 2004, quatro bombas explodem nos transportes públicos do centro de Londres. Em seguida, o governo dinamarquês condena 
publicamente os atentados e conclama os líderes de associações islâmicas a se manifestarem no mesmo sentido. Entretanto, por mais que haja uma postura de neutralidade na atuação do aparato jurídico e do gabinete do primeiro ministro, a opinião pública dinamarquesa apóia cada vez mais claramente a repressão contra os muçulmanos.

Nesse contexto, outro fenômeno também assola a opinião pública com bastante força: o medo de criticar o islã. E é justamente em reação a este "fato" que o Jyllands-Posten produz o número especial com os desenhos de Maomé. O jornal teria se inspirado em uma história de auto-censura contada por um escritor militante que publica histórias sobre o islã para adolescentes e que não teria conseguido encontrar ilustradores para sua nova obra sobre a vida de Maomé. Diante de tal dificuldade, o escritor chegou a procurar o sindicato dos ilustradores da Dinamarca, mas sem sucesso. Mais tarde, finalmente encontrou um artista disposto a ilustrar seu livro, mas que entretanto se recusara a assinar os desenhos. Ao tomar conhecimento dessa história, o redator do Jyllands-Posten recruta uma equipe de jornalistas para realizar uma pesquisa que, por seu turno, encontra diversos desenhistas que também se recusam a fazer imagens de Maomé. Eis que o jornal decide montar uma "experiência in vivo" para testar a hipótese da auto-censura dos artistas: escreve aos quarenta membros do sindicato dos ilustradores da imprensa e os propõe desenhar Maomé "como eles o vêem" (:76). Doze entre eles enviam seus desenhos. Eles são publicados com diversos artigos, sob o título "As faces de Maomé".

Favret-Saada inicia o quarto capítulo comentando o conteúdo do editorial e dos artigos que compõem o dossiê do Jyllands-Posten, e destaca que apesar de seu tom crítico e arrogante - que pode se apreendido já no título do editorial "A ameaça vem das trevas" -, não se pode afirmar que há nele racismo (:83). Os desenhos elaborados pelos chargistas também são analisados rapidamente pela autora, que prefere descrevê-los a publicá-los. Entre eles, o mais problemático seria aquele que mostra o rosto de Maomé com um turbante que é uma bomba com o pavio aceso. Esta representação em particular é frequentemente lida por muitos muçulmanos como uma declaração racista que equipara islamismo e terrorismo.

Mesmo com um conteúdo contundente e controverso, o dossiê não provocou reações da imprensa dinamarquesa nas duas semanas seguintes à sua publicação. Entre os muçulmanos, uma reação começa a tomar corpo. Na cidade onde o jornal é publicado, Aarhus, o imã Raed Hlayhel fixa exemplares do jornal nos muros da mesquita. Em seguida, ele se reúne com imãs de Copenhague e com o líder da Sociedade Islâmica da Dinamarca, e juntos fundam o Comitê Europeu em Defesa do Profeta, cuja demanda inicial é um pedido público de desculpas pelo jornal

Os desdobramentos seguintes se relacionam diretamente à mobilização do Comitê em instâncias políticas internacionais, sobretudo junto a organizações islâmicas e líderes de países muçulmanos. Em resposta, o Primeiro Ministro Rasmussen declara que somente a justiça possui meios para influenciar a imprensa e que a liberdade 
de expressão é "o fundamento mesmo da democracia dinamarquesa", assim como a tolerância religiosa e o respeito às religiões (:95). O passo seguinte tomado pelo Comitê em Defesa do Profeta em conjunto com outras organizações islâmicas é apresentar uma queixa na justiça acionando as leis dinamarquesas anti-racismo e anti-blasfêmia. Concomitantemente a isso, muitas potências estrangeiras começam a criticar publicamente o governo dinamarquês. Apesar de pesquisas de opinião indicarem que a maioria da população dinamarquesa considera a liberdade de expressão algo mais importante do que as tradições religiosas, líderes de partidos dinamarqueses de direita e esquerda também criticam o posicionamento do Primeiro Ministro, e clamam por uma maior abertura para o diálogo com as lideranças religiosas.

No quinto capítulo, Favret-Saada demonstra que todas as ações dos líderes religiosos e políticos envolvidos finalmente eclodem em uma controvérsia de dimensões imprevistas na medida em que novos atores entram em cena. A progressiva adesão de outras organizações, como a Liga Árabe, a Organização da Conferência Islâmica (OCI), e os líderes de diferentes religiões, centros universitários e partidos políticos, ampliou drasticamente o número de atores divulgando mensagens contrárias à publicação. Este alargamento da controvérsia deveu-se em grande medida a uma viagem a diversos países árabes realizada pelos membros do Comitê Europeu em Defesa do Profeta. Nesta ocasião, a delegação porta um dossiê com as imagens das charges, entre outros documentos, que fazem circular entre líderes políticos e religiosos. Em diversas oportunidades, manifestam-se em programas de rádio e televisão, acusando o governo dinamarquês de fomentar uma guerra contra o islamismo e conclamando os fiéis muçulmanos a apoiarem a causa pela defesa da honra do Profeta, garantindo o pedido de desculpas e o compromisso de que não haja outras profanações no futuro $(: 110)$.

As pressões sobre o governo se mantêm até que, em seu discurso de ano novo proferido em dinamarquês e árabe nos primeiros dias de janeiro de 2006, Rasmussen condena todas as manifestações de racismo ou de segregação e afirma vagamente que os limites da liberdade de expressão eventualmente são ultrapassados. Ainda que líderes religiosos e políticos muçulmanos tenham recebido positivamente este discurso, a divulgação na mídia dinamarquesa da viagem do Comitê em Defesa do Profeta pelo Oriente Médio reacende os ânimos, a ponto de gerar reações na Noruega, onde um jornal republica os desenhos. Segue-se então uma nova rodada de protestos, sobretudo através das "novas mídias" (blogs, SMS, e-mails etc.). Para Favret-Saada, "essas novas mídias contribuem de agora em diante para a internacionalização do caso: elas ampliam as acusações contra os blasfemadores - os desenhistas, os jornais e seus Estados - tanto quanto os protestos e as sanções do mundo muçulmano, elas mobilizam os militantes e mantêm o público por perto" (:121). Finalmente, uma reação muito maior é orquestrada na Europa: em primeiro de fevereiro de 2006, dezenove grandes jornais da Alemanha, Países Baixos, Suíça, Itália, Espanha, Portugal e França publicam os doze desenhos novamente. Com 
exceção dos jornais da Grã-Bretanha, mais 60 jornais de diversos países europeus republicam os desenhos nos seis dias seguintes.

O sexto capítulo apresenta as estratégias utilizadas pelos atores envolvidos na controvérsia no sentido de dissipar os conflitos abertos. Por seu lado, governantes de países muçulmanos passam a exortar a restrição da revolta dos muçulmanos às formas legais. Nesse mesmo sentido, a OCI propõe leis anti-blasfêmia e anti-islamofobia na reunião de elaboração da carta do Conselho dos Direitos do Homem encabeçada pela ONU e pelo Parlamento Europeu. Da parte do governo dinamarquês, foram tomadas medidas com a finalidade de "demonstrar a boa vontade de seu país" (:145). Estabelece-se diálogo com líderes religiosos de diversos países; uma delegação de religiosos dinamarqueses viaja ao Egito para dialogar; são feitas contribuições financeiras para instituições de apoio ao diálogo intercultural; e um colóquio é organizado em Copenhague para discutir os estereótipos culturais.

Favret-Saada ressalta que apesar do clima de "boa vontade" que paira sobre o debate nesse momento, estabelece-se um "diálogo de surdos" (:144), no qual os muçulmanos avançam em demandas normativas contrárias aos "princípios democráticos", enquanto o governo dinamarquês, a ONU e o Parlamento Europeu mantêm a posição "pró-debate", sem entretanto atender às demandas dos líderes muçulmanos. Isto fica evidente na reunião que define a versão final da Carta do Conselho dos Direitos do Homem, onde a União Européia se recusa a adotar qualquer uma das medidas reclamadas pela OCI. Por fim, "o único sucesso dos defensores 'dos profetas e das religiões' será uma referência vaga ao respeito às religiões (sem ligação explícita com o caso dos desenhos de Maomé) inserido em um comunicado da Assembléia Geral das Nações Unidas" (:144).

Num epílogo que antecede a conclusão de Comment Produire une crise moundiale, Favret-Saada destaca algumas conseqüências da controvérsia para as relações entre os muçulmanos residentes na Dinamarca e o governo deste país. Para além da renovada tentativa de diálogo por parte do governo, a autora sublinha o fato de cidadãos e estrangeiros vivendo na Dinamarca manifestarem seu pertencimento ao Islã e sua recusa à liderança dos envolvidos. Foram criados fóruns de muçulmanos críticos e outros movimentos que revelaram a grande diversidade de posições entre os muçulmanos a respeito dos desenhos, dos 'valores dinamarqueses', da integração. Para a autora, esta diversidade de opiniões faz desmoronar "a ficção de uma 'comunidade muçulmana' unânime, soldada em torno daqueles que se autoproclamaram seus líderes naturais (...)" (:151).

Já nas conclusões, Favret-Saada traça as conseqüências mais gerais da controvérsia em torno dos desenhos do Profeta Maomé. Entre as "lições" tiradas a partir do caso, a autora conclui que "mesmo com as dificuldades encontradas por esse ou aquele governo para acalmar suas populações e também diante do fracasso diplomático da OCI,(...) o mundo muçulmano experimentou a virtude da coesão" (:167). Para o ocidente, também houve uma "boa lição": "atingir o islã (seja sob a 
forma de uma crítica aos muçulmanos) pode custar caro - vidas, bens, muito dinheiro" (:167). E finaliza: "quanto ao Jyllands-Posten, duramente em prova ao longo do caso, ele mais do que verificou sua hipótese segundo a qual os artistas se autocensurariam com medo do islamismo: nós podemos razoavelmente apostar que não se verá mais caricaturas do Profeta nos próximos anos" (:169).

Ao reconstruir a controvérsia pública em torno da publicação dos doze desenhos de Maomé, Favret-Saada põe em relevo e denuncia a tentativa de capitalização do debate por parte de líderes religiosos islâmicos europeus e do Oriente Médio. Assim, revela de modo eficaz o protagonismo dos denunciadores muçulmanos no processo de avaliação pública dos desenhos e o papel dos mesmos na condenação dos "produtores" ou "apoiadores" da empreitada em nome da preservação da honra do Profeta Maomé e da fé do "povo muçulmano". Por outro lado, ao reclamar os devidos limites entre interesses religiosos de grupos islâmicos e princípios democráticos dos Estados seculares, Favret-Saada contribui diretamente para a definição de tais limites, construindo-os como inconciliáveis, à moda dos atores políticos dinamarqueses (chefes de Estado e jornalistas), justamente os quais ela pretende "posicionar".

Além disso, deixa-se quase completamente de lado o papel que as imagens desempenharam no debate, pois além de descrevê-las rapidamente, Favret-Saada não analisa as especificidades dos desenhos, os diferentes modos de circulação de tais imagens e as conseqüentes recepções entre fiéis muçulmanos. No mesmo sentido, uma outra ausência perceptível diz respeito aos muçulmanos declaradamente ofendidos com os desenhos do Profeta, mas que não são seguidores dos líderes religiosos dinamarqueses.

\section{Notas}

1 Favret-Saada, Jeanne. (1977), Les Mots, la Mort, les Sorts. Paris: Gallimard.

2 Favret-Saada, Jeanne. (1991), "Rushdie et Compagnie. Prealables a une Anthropologie du Blaspheme". Ethnologie Francaise, 3.

3 Comunicação apresentada em maio de 2007 no seminário "Antropologia dos dispositivos cultuais" organizado pela École des Hautes Études en Science Sociales, na cidade de Marseille. Disponível para acesso em http://shadyc.ehess.fr/docannexe.php?id=499. Consultado em 5/3/2009.

Paola Lins de Oliveira (paolalins@gmail.com)

Doutoranda em Antropologia pelo Programa de Pós-Graduação em Sociologia e Antropologia da Universidade Federal do Rio de Janeiro e Pesquisadora do ISER. 